\title{
ARRITMIAS Y RECOVECOS DEL POST-NEOLIBERALISMO EN AMÉRICA LATINA
}

\author{
Raúl González Meyer ${ }^{1}$
}

\section{Resumen/Abstract}

Este artículo introduce la pregunta si América Latina está transitando hacia una época de postneoliberalismo y, a la vez, en qué dirección sería esa eventual transición. Un tiempo fundacional de esta pregunta, ubicada en la "superestructura política" del sistema, fue el de la emergencia e instalación desde el inicio del siglo XXI de un grupo apreciable de gobiernos que dentro de las categorías tradicionales fueron entendidos de "centro-izquierda", antecedidos de una serie de movilizaciones y expresiones colectivas como el "caracazo" venezolano (1998), las "guerras" del agua y del gas en Bolivia (2002), movimiento anti-clase política en Argentina (2001) y que generaron, al respecto, una serie de interpretaciones sobre el significado transformador que portaban. La pregunta lleva a establecer los aspectos definitorios del neoliberalismo, particularmente en América Latina, para efectos de saber cuán neoliberal se hizo el continente. La pregunta sigue viva, pero reformulada en tiempos más recientes, en que ha surgido una detención y reversión de esa "onda" política y una disminución de la popularidad de algunos de sus procesos exponentes dando lugar a la emergencia de gobiernos que discursivamente retoman banderas liberales previas. ¿Expresa esto último que la tendencia hacia un post NL es con ciclos, no lineal?; ¿operan estos procesos más recientes sobre un fondo ya desplazado en dirección post neoliberal y estrechan los márgenes de reversiones?

Palabras clave: neoliberalismo, postneoliberalismo, desarrollo, gobiernos progresistas, América Latina

\section{ARRHYTHMIAS AND RECESSES OF POSTNEOLIBERALISM IN LATIN AMERICA}

This article introduces the question if Latin America is moving towards a time of post-neoliberalism and, at the same time, in what direction would that eventual transition be. A foundational time for this question, located in the "political superstructure" of the system, was that of the emergence and installation since the beginning of the 21st century of an appreciable group of governments that within the traditional categories were understood as "center-left." That governments were preceded by a series of mobilizations and collective expressions such as the "caracazo" Venezuelan (1998), the "wars" of water and gas in Bolivia (2002), anti-political class movement in Argentina (2001) that generated, at respect, a series of interpretations about the transformative meaning they carried. The question leads to establishing the

\footnotetext{
${ }^{1}$ Chileno, Universidad Academia de Humanismo Cristiano. E-mail: rgonzalezm@,docentes.academia.cl

Recibido el 15 de junio de 2019

Aceptado el 2 de julio de 2019
} 
defining aspects of neoliberalism, particularly in Latin America, in order to know how was made neoliberal the continent. The question is still alive, but reformulated in more recent times, when there has been a detention and reversal of that political "wave" and a decrease in the popularity of some of its exponential processes, giving rise to the emergence of governments that discursively retake previous liberal flags. Does the latter express that the trend towards post neoliberalism is with cycles, not linear? Do these more recent processes operate on a fund already displaced in the postneoliberalism direction and narrow the reversion margins?

Keywords: neoliberalism, postneoliberalism, development, progressive governments, Latin America

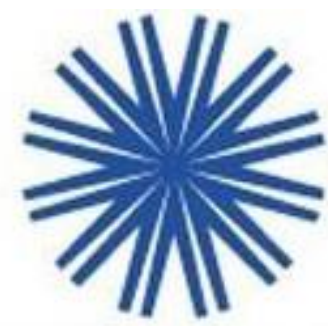

\section{Introducción}

Este documento introduce a la pregunta si América Latina está transitando hacia una época de post-neoliberalismo y, a la vez, en qué dirección sería esa eventual transición. Un tiempo fundacional de esta pregunta, ubicada en la "superestructura política" del sistema, fue el de la emergencia e instalación, desde el inicio del siglo XXI, de un grupo apreciable de gobiernos que dentro de las categorías tradicionales fueron entendidos de "centro-izquierda", antecedidos de una serie de movilizaciones y expresiones colectivas como el “caracazo" venezolano (1998), las “guerras” del agua y del gas en Bolivia (2002), movimiento anti-clase política en Argentina (2001), los que generaron una serie de interpretaciones sobre el significado transformador -en un sentido anti-neoliberal- que portaban (Marthoz y Duterme, 2007; Ramírez, Avritzer y Parenti, 2007). La pregunta sigue viva, pero reformulada con posterioridad, en un tiempo caracterizado por la detención y reversión de esa "onda" transformadora y una disminución de la popularidad de algunos de sus procesos exponentes, dando lugar a la emergencia de gobiernos que discursivamente retoman banderas liberales previas. ¿Expresa esto último que la tendencia hacia un post-neoliberalismo es en ciclos, no lineal? ¿operan estos procesos más recientes sobre un fondo ya desplazado echin dirección post-neoliberal y estrechan los márgenes de reversiones?

La pregunta lleva a establecer los aspectos definitorios del NL, particularmente en América Latina, para efectos de saber cuán neoliberal se hizo el continente ${ }^{3}$. Ello permitiría describir en qué sentido el NL impactó y modificó al continente - estableciendo nuevas maneras de "ser" y "reproducirse" los distintos

\footnotetext{
${ }^{2}$ Chávez-Maduro en Venezuela; Vázquez-Mujica en Uruguay; Morales en Bolivia; Lula-Roussef en Brasil, Lugo en Paraguay; Ortega en Nicaragua; Kichnner-Fernandez en Argentina; en sus inicios Humala en Perú.

${ }^{3}$ Esto no supone la hipótesis previa que el NL latinoamericano tenga una determinada singularidad respecto de lo que se definen como los rasgos claves generales de dicho orden social (económico, político y cultural), sino, simplemente señalar que, en tanto proyecto y programa de acción, es necesario analizar con qué contenidos y peso se "instaló", insertó y maduró en el continente, dentro de la historia más larga de este, en comparación con las experiencias del NL metropolitano (Preston, 1999).
} 
países- y evaluar si esos aspectos han entrado en algún grado de crisis, y si están siendo significativamente modificados por procesos que estarían definiendo un nuevo momento histórico que llamamos, genéricamente, post-neoliberalismo.

\section{Doctrina, orientaciones, impulsos del NL en América.Latina}

El NL doctrinal en su límite máximo es la utopía (siempre con algunos topes) de una economía (prácticas de producir, distribuir, consumir, ahorrar, invertir) movida por conductas utilitaristas, autorregulada por el mercado y de una sociedad institucionalmente organizada para facilitar y expandir esas conductas y ese tipo de regulación. El funcionamiento y despliegue de los actos mercantiles debe, por un lado, devenir lo más autónoma posible de la "interferencia” social y política y, por otro, “ordenar" el comportamiento natural de los sujetos devenidos empresarios, trabajadores y consumidores (Marechal, 2005). Es decir, el NL no es solo la aceptación del mercado, institución muy antigua, como principio de regulación e integración económica (Polanyi, 2003), sino establecerlo como principio superior y rector ${ }^{4}$. La libertad individual, la eficiente asignación de recursos, la perfecta coordinación económica y la primacía de la soberanía del consumidor, son los aspectos de justificación más conocidos e importantes de tal doctrina (González Meyer, 2013). Un supuesto las más de las veces implícito es que "los jugadores” en el mercado no tienen poderes suficientemente grandes como para controlarlo, al menos, parcialmente.

Su contracara, es el descredito del Estado en las tres orientaciones socio-económicas que acrecentaron su peso en el siglo XX: keynesiana, de bienestar y desarrollista ${ }^{5}$ (González Meyer, 2013). De allí la elaboración de un programa de acción que tuvo el carácter de una cruzada anti-estatal en que el Estado y

\footnotetext{
${ }^{4}$ Es importante notar, que no debe inferirse que toda discusión y valorización del mercado debe necesariamente expresar a la doctrina NL. Recordemos, como ejemplo de ello, la discusión que en los años 60 se dio en los países socialistas de la época, acerca del rol que debía tener el mercado en tal economía. Economistas soviéticos, checoeslovacos, polacos y húngaros, principalmente, discutirán como usarlo en función de una serie de problemas de la economía socialista planificada, como la adecuación de los bienes de consumo a las demandas reales de las personas (Nove, 1994). La cuestión del mercado en la economía, por lo tanto, en tanto institución antigua "pre-moderna", no es algo solo propio de la visión neoliberal e incluso solo propio de la experiencia capitalista. Lo que sí es propio de la visión NL y que retoma visiones del siglo XIX -sobre todo de la economía política inglesa- es la creencia y optimismo en esa capacidad auto-reguladora y autosuficiente del mercado.

${ }^{5}$ La crítica y la propuesta NL al Estado del siglo XX -el del camino a la servidumbre- debe estar analíticamente ordenada a la crítica a su rol desarrollista (protagónico en la esfera de la expansión económica y especialmente de la industrialización), a su rol benefactor o de bienestar (protagónico en la producción de servicios sociales considerados componentes de los derechos económico y sociales y no sujetos a una regulación mercantil), y a su rol keynesiano, a través de la política fiscal y monetaria (capacidad de actuar frente a los ciclos económicos y el desempleo). Entre estos roles hay complementariedades, sinergias e intersecciones; pero, también, tensiones.
} 
su combustible motriz, la política, son puestos en el lado de la irracionalidad. Para el NL, la irracionalidad del Estado y de la política debían ceder lugar a la máxima mercantilización posible de la sociedad ${ }^{6}$.

Lo anterior es parte del postulado general del NL que se expande también hacia América Latina. Pero es interesante señalar dos hechos relacionados, que le dan a éste un carácter más continental. El primero, más genérico, es que el análisis NL establece con fuerza una relación estrecha entre Estado y subdesarrollo (latinoamericano), no porque aquel haya hecho poco, sino por haber hecho demasiado. Ello lo transformó en una máquina hipertrofiada, mal empresario, dirigista, paternalista, monopolista, financieramente irresponsable, causante de inflaciones y ahogador de la iniciativa privada. En síntesis, según las elites NL, especialmente economistas, es la intervención estatal sobre el mercado y los precios, lo que explicaría el retardo en los países latinoamericanos (Devés, 2003) ${ }^{7}$.

Además -en contradicción con su individualismo metodológico, que intenta explicar la economía y la sociedad ("el todo") desde la agregación de individuos envueltos en numerosos contratos-, el NL generó una economía política de ese subdesarrollo, en la medida que todos los precios y mercados intervenidos eran explicables por la acción de grupos con capacidad de presión. Detrás de los bajos precios agrícolas estaba la presión de las clases urbanas, empresarios y trabajadores; detrás de los aranceles, empresarios rentistas demandadores de proteccionismo; detrás de los salarios altos, sindicatos urbanos poderosos y políticos populistas que los fijaban por arriba del "natural" de la oferta y demanda; detrás de la expansión estatal, una tecnocracia pública y clases medias que buscaban reproducirse en el empleo público (González Meyer, 2004). Es decir, la separación del buen camino era el resultado de la acción de grupos -algo más que la suma de individuos- que llevaban también a América Latina del siglo XX hacia el totalitarismo y la ineficiencia postulada por Hayek en Camino a la Servidumbre (Hayek, 2008). La disminución del peso del Estado en la estructuración y dinámica económica era considerada por los NL una tarea primordial, en

\footnotetext{
${ }^{6}$ La crítica marxista al carácter anárquico del capitalismo, expuesto a irracionales crisis de sobreproducción, a equilibrios ex-post entre ofertas y demandas, que significaban perdidas de productos, al no poder el valor de cambio transformarse en valor de uso, es invertida, y la única racionalidad eficiente - además libertaria- es aquella inmanente al funcionamiento del mercado (Friedman, 2008).

${ }^{7} \mathrm{La}$ lectura NL de la historia económica de Chile es ejemplar. Para sus portavoces, su retardo secular estuvo asociado a una acción estatal que, junto al problema que significaba su propia expansión, controló precios básicos de la economía, generando problemas estructurales correspondientes: la fijación estatal de la tasa de interés, desincentivó el ahorro nacional, no permitió disponibilidad de capital nacional y obligó a endeudamiento externo; la fijación estatal de los precios agrícolas, desincentivo la inversión en agricultura y llevo al país a una crisis agraria, y a la creciente necesidad de importar alimentos; la fijación estatal de un bajo tipo de cambio, desincentivo las exportaciones, más allá del cobre, y generó una permanente crisis de balanza comercial y de pagos; la fijación de aranceles, produjo industria ineficiente por protegida; por último, la fijación de salarios altos y tendencia condujo al uso de tecnología demasiado "capitalística" poco generadora de empleo. Soltar esos precios se transformaba en la base, por lo tanto, de una economía con mayor ahorro e inversión, mejor industria, con más exportaciones, con más empleo y con una agricultura moderna. (de Castro, 1992).
} 
pos de avanzar hacia el desarrollo y debilitar o cambiar la ideología de grupos que por sus orientaciones habían construido -al menos como cómplices- aquello que había que transformar ${ }^{8}$. El tipo de Estado que intenta constituirse es "meta-regulador" en tanto "entidad responsable de crear el espacio para la legitimidad de los reguladores no estatales" (Svampa, 2016). Sin embargo, como era obvio, esa realidad favoreció a aquellos agentes privados que tenían más peso en el mercado y, dadas otras orientaciones adicionales, la instalación de capitales extranjeros, de grandes corporaciones y la mercantilización de bienes públicos.

Bajo ese análisis, resulta comprensible otra característica del NL presente en América Latina, fuertemente promovido por los economistas neoliberales: una idea de democracia política limitada, no desde la argumentación de la "seguridad nacional", pero en relación de complementariedad con ella. La esfera política, como lugar de expresión y negociación de intereses y desde la cual se busca intervenir sobre el orden socio-económico, es leída negativamente, dado que ello significa una interferencia indeseable sobre los mercados, en el que diferentes grupos buscan obtener rentas de la economía -constituyen coaliciones distributivas- no a través del aumento de la productividad (su aporte a la economía) sino consiguiendo fijaciones de precios, subsidios, impuestos a los competidores, posiciones monopólicas, etc., debilitando al mercado para que exprese de manera correcta las escaseces relativas de los bienes y factores. La única posibilidad de "mercado libre" es una política y una sociedad organizada (grupos de interés) que sean de bajo perfil (Marechal, 2005). Así, la lectura de la organización y demandas populares como factor democratizador en el siglo XX -o de ampliación de la afirmación ciudadana- es releída como aumento de la distorsión del mercado que, es, a la vez, el lugar donde ocurre y se expresa la libertad. Así, las luchas por una mejor distribución de los ingresos a través del mejoramiento de los salarios serán generalmente releídas como un intento de desprender al salario de la real productividad del trabajo, fertilizadas por la tendencia al populismo en el continente, caracterizado como enemigo central de la buena y ordenada conducción económica.

En ese espacio "libre" debe actuar quien es, para el NL, el agente protagónico de una modernización y desarrollo, que había sido neutralizado y desnaturalizo durante el siglo XX latinoamericano: un

\footnotetext{
${ }^{8}$ Este estatismo para el NL no era fácil de extirpar pues ello era el resultado de una tradición y una cultura política estatista, forjada desde la colonia (de Castro, 1992). Esta idea de la dificultad de instalar una lógica liberal plena se encuentra también presente en el diagnostico crítico que M. Friedman realiza de los gobiernos de R. Reagan y M. Thatcher acerca de sus limitaciones para derrotar a la burocracia estatal durante sus respectivos gobiernos.
} 
empresariado dotado de una verdadera empresarialidad (González Meyer, 2004). El empresario y la empresarialidad privada, como sujeto y como conducta, son repuestos por el NL en el lugar central de la acumulación de riqueza, guiados por esos faros que son los precios, que permiten una conducta empresarial genuina, competitiva e innovativa y que significa una refundación de las elites empresariales tradicionales, mal acostumbradas a la protección y favores estatales ${ }^{9}$. Un empresariado "más moderno", situado en un medio cultural más abierto al cambio, a la ciencia y la tecnología. Menos "pacato" en moralidad y en resguardo de valores tradicionales; valorizador de la actitud de competir, ganar y acceder al éxito; dotado de un nuevo espíritu más agresivo y mundializado.

Lo anterior es conectado con otro componente definitorio del NL: la ampliación del "campo de acción" del empresariado y el mercado y la ruptura de la figura del Estado Bienestar. Ahora, los agentes privados podían ser mucho más protagonistas en la producción de servicios como salud, educación, vivienda, transporte, seguridad social; estos podían y debían ser áreas de despliegue del capital privado, que respondiera en grado mayor a procesos de oferta y demanda solvente en el mercado. También, esto podría tomar la forma de concesiones provenientes del sector público. Esta acción emprendedora privada, en búsqueda de lucro y bajo la lógica competitiva de mercado, debía invadir áreas de acción antes "irracionalmente" semi-vedadas, disminuyendo el peso del Estado, de la política y de las tecnocracias públicas, de los partidos; finalmente, del "ogro filantrópico" de Octavio Paz.

Todo ello, inscrito en la idea envolvente de valorar y promover una cultura de la empresarialidad, que abarca, en una expresión singular del NL latinoamericano, al amplio mundo popular urbano, así leído en El Otro Sendero de H. de Soto. (De Soto, 1986). El ideario N.L. y sociedad (economía) popular latinoamericana, fueron conectados. En las barriadas pobres limeñas, en una visión que se ofrecía de alcance continental, no había principalmente, habitantes o pobladores calificables de marginales, revolucionarios y/o comunitarios, volcados hacia dentro, informales por naturaleza, o ignorantes de las leyes. Ellos eran emprendedores individuales, instrumentalmente asociados, que producían viviendas, servicios de transportes, comercios, manufacturas, y otros (de Soto, 1986). En ese quehacer, dichos empresarios-pobladores se veían obligados a esquivar al Estado normativo y burocrático para poder sacar

\footnotetext{
${ }^{9}$ Se invierte la lectura de los teóricos de la dependencia. Para estos, el rol del Estado y otras clases en el proceso de modernización económica latinoamericana y de la vía socialista, se argumentaba en parte por la inexistencia de un empresariado (burguesía) nacional (nacionalista) que pudiese encabezarla - dada su dependencia tecnológica, financiera, política, lo que la convertía en la "lumpen burguesía" de A. G. Frank. Para el NL, el estatismo alimentado por el desarrollismo, el keynesianismo, el populismo, el socialismo, había sido lo que asfixió e impidió crecer a un empresariado innovador y fuerte.
} 
su empresarialidad adelante. Como señaló Bustamente Belaunde, la informalidad era "la marcha silenciosa pero inexorable que una gran mayoría de peruanos ha emprendido en busca de la libre empresa y del desarrollo de su iniciativa personal" (citado en Devés, 2003: 288). ${ }^{10}$

Esta re-lectura de los pobladores urbanos se conectaba con otra que buscaba revolucionar la (auto) representación del proletario dependiente. Se trataba de construir la idea y subjetividad de un trabajador nuevo, flexible, administrador de su propio tiempo y, en cierto grado, un "empresario de sí mismo", funcionando bajo el principio de la zanahoria y el garrote, autocontrolándose, a través de los premios y castigos de mercado, expresados en ingresos. Ello no era visto por los NL como precariedad e inseguridad para los trabajadores, sino como la nueva realidad en la que estos debían desenvolverse; siempre al frente de variadas alternativas y oportunidades para decidir, entre las cuales está, también, la opción de aumentar su capital humano.

El NL se instaló con el sello de alejarse de toda idea nacionalista en el campo socio-económico, como una propuesta que podríamos denominar "post-nacionalista". Se aparta de una estrategia fundada en un empresariado nacional y del principio de una propiedad y gestión, nacionales, de los recursos naturales u otros considerados "estratégicos". La fundación de un empresariado "moderno", competitivo, se la piensa entrecruzada con el empresariado y capital trasnacional, como condición para acceder al espacio económico mundializado. Empresariado y capital son fuerzas universales y lo importante es que se localicen en el país, no su procedencia. No hay mayor referencia crítica al poder asimétrico de los agentes y países en el mercado mundial, a las multinacionales o a situaciones como imperialismo o dependencia. El NL venezolano, Carlos Rangel, en el Del buen salvaje al buen revolucionario planteaba que los países con falta de estima y confianza en sí mismos y en sus posibilidades de desarrollo dentro del sistema mundial capitalista, "se inclinan a aceptar como explicación de sus problemas, las tesis sobre el imperialismo y la dependencia" (citado por Devés, 2003: 283). El NL fue un intento de globalización privada, liberal, que en los hechos solo podía ser comandada por las grandes empresas y capitales. Esto

\footnotetext{
${ }^{10}$ Desde esta perspectiva, las denuncias desde la modernización "tradicional" de que había una involución modernizadora porque aumentaba el sector informal urbano era leído o releído desde el liberalismo económico no como negación (es decir por no encontrar espacio en las fábricas o servicios formales de la economía) sino por afirmación en tanto expresión o potencial de empresario popular, con "instinto" de emprendurismo. Es un sector que sigue constituyendo una masa enorme de gente y que ha sido durante las últimas 5 a 6 décadas la base material de lecturas diferentes: marginales, informales, empresarios populares, economía solidaria, microempresarios.
} 
incluía la llegada de la cultura extranjera de países "avanzados", entendida como promotora de la innovación y la modernización ${ }^{11}$.

El abandono de una orientación nacionalista -en lo socio-económico- se expresa en el abandono de la industria nacional como idea eje de la estrategia y política económica. Ello va a ser entendido como un voluntarismo y una intromisión desmedida del Estado en la dirección de la economía y de una serie de decisiones -creación directa de empresas y establecimiento de aranceles y subsidios-, juzgados como la base de economías nacionales ineficientes, que no se habían desarrollado de acuerdo a sus "ventajas comparativas" en el espacio mundial, indicadas por los precios de mercado. Si ello llevase a una "reprimarización" de las economías latinoamericanas -como fue criticado posteriormente- ello no habría que tomarlo como un problema, sino como la mejor vía de desarrollo ${ }^{12}$.

Junto a estos elementos de "doctrina", la comprensión completa del significado del NL en América Latina debe considerar el momento histórico del continente en los años 60-70. Al respecto, podemos interpretar que el NL fue una específica respuesta a las dificultades y contradicciones que enfrentaba la industrialización latinoamericana en los años 60-70 y a los conflictos sociales que le daban cuerpo y emanaban de ella. Se expresaba un necesario pero difícil pasaje a un estadio más complejo de industrialización, que abriera horizontes de mejoramiento económico, que oxigenara al sistema político, y que respondiera a expectativas, organizaciones, y capacidades de presión, acrecentadas, en diversos países del continente ${ }^{13}$.

En ese cuadro y dinámica históricos, parece ser correcto decir que se bosquejaban dos cauces principales posibles: uno de economías más estatales, nacionalizadas o socialistas, con un rol central de la política y de la planificación, desde donde se captara, se generara y se administrara una mayor proporción del "excedente económico"; u otro que facilitara el redespliegue industrial -inversiones, deslocalizaciones de empresas, instalaciones de filiales, alianzas con capitales nacionales- desde los países centrales hacia los

\footnotetext{
${ }^{11}$ Eso puso en conflicto al neoliberalismo con sectores nacionalistas que participan de golpes militares de derecha -necesarios para enfrentar movimientos y organizaciones sociales pro "comunistas"- pero que no tienen en mente un proyecto económico y cultural liberal y que definen su postura a partir de la afirmación de un "interés nacional".

${ }^{12}$ A la manera de las teorías clásicas inglesas del siglo XIX, que ya habían sido fuertemente contestadas por el estructuralismo latinoamericano (CEPAL), y en el propio siglo XIX por la escuela histórica alemana.

${ }^{13}$ Una significativa literatura latinoamericana sobre desarrollo, a la época, se referirá al agotamiento de una primera fase de industrialización, etapa de "sustitución fácil", y a las dificultades o condiciones para pasar a una fase de industrialización más compleja que se refería a nuevos sectores y tecnologías (Prebisch, 1963).
} 
periféricos, por parte de las empresas trasnacionales y las fusionara o combinara con las economías nacionales dependientes (Cardoso y Faleto, 2011: 179-211). Proceso, por lo demás, que ya había comenzado, mostrado por la CEPAL y fuertemente denunciado por los teóricos de la dependencia como un signo de desnacionalización y dependencia de la industria latinoamericana. Lo anterior no parece haber existido como un "dilema formal" entre quienes analizaban y pretendían intervenir la realidad del continente, sino que era un dilema real construido desde la dinámica del conflicto social histórico. Desde este, se bosquejaban y proyectaban esas alternativas principales, cómo formas posibles de conducir la historia en una u otra dirección (dos Santos, 2011: 145-178). Es decir, en cierto grado significativo, la acción/ideas de las clases, grupos, agentes, se podían ordenar en torno a esos cauces posibles, más allá de su grado de elaboración o nitidez, en sus propios discursos.

Desde esa perspectiva, el NL fue, por un lado, el programa de acción que abrió un cauce para que fluyera el conflicto señalado; pero que termina abriendo un tercer cauce, con intersecciones variables, según países, con el segundo antes descrito, en que lo común entre ambos fue la clausura de la posibilidad del primero. Ello necesitó grados altos de represión y terror, más o menos intensos, según países, hacia quienes sostenían otras alternativas. Influyó también, en los años 80, la situación de endeudamiento extremo e hiperinflación de muchos países latinoamericanos ${ }^{14}$, lo que disminuyó los márgenes de acción de sus gobiernos, más allá de la acusación de entreguismo que pudiese hacerse, frente a las ordenanzas emanadas de instituciones financieras internacionales que abrazaron con intensidad una ortodoxia y programa liberal radical, lo que llevó a imponer políticas nacionales muy liberales como vía de lograr equilibrios macroeconómicos Así, se orientó el manejo económico por una agenda que privilegió el ajuste fiscal, la apertura externa, la liberalización comercial y financiera, la desregulación del mercado del trabajo y las privatizaciones.

Este "tercer cauce" abandonaría, al menos parcialmente, según países, el imaginario y la acción industrialista, algo que no parecía posible en el escenario de los años 60-70 en que la disputa central podía caracterizarse acerca de las "vías de industrialización”. El NL levanta una crítica radical a una industrialización voluntarista y al proteccionismo que la acompañó, juzgada ineficiente y cuyo costo lo habrían pagado consumidores comprando productos nacionales más caros. Fue un cauce revolucionario

\footnotetext{
${ }^{14}$ Un caso extremo fue Bolivia en que la deuda de 1984 representaba el $420 \%$ de las exportaciones anuales, y la hiperinflación se situó en un $11.750 \%$ anual en 1985 .
} 
sostenido en bases convencionales y conservadoras de la teoría económica ${ }^{15}$ que puede también ser leído, más allá del impacto social sobre vastos grupos populares, como una derrota del empresariado industrialista, de cierto militarismo nacionalista y de clases medias públicas desarrollistas.

En esa contextualización y perspectiva histórica, el NL se engarzó a la historia más larga que busca modernizar América Latina. Es en su nombre que se orienta la acción, pero esta vez bajo una restauración capitalista más pura, condenando todo afán distributivo a despreciable populismo y a todo lo que amenazase la tranquilidad de los empresarios, a disminución de la inversión y a creación de pobreza.

\section{Cuán impreso y hegemónico se hizo el NL}

Lo escrito antes está situado en el plano del ideario y los propósitos NL; en las políticas que alentó y las fuerzas emergentes que empujó, en lo que buscó destruir o debilitar; así como en el sentido histórico que tuvo. ¿Pero cuánto se instaló efectivamente en América Latina, en su materialidad e idealidad? ¿Cuán neoliberal se transformó América. Latina en su modo de funcionamiento y en su manera de ser? La respuesta a ello está en curso y necesita distinguir casos. Ello está ocurriendo frente a nosotros.

Podemos partir afirmando que hay aspectos decisivos en los que ha ocurrido un asentamiento del NL en América Latina, aunque no es exclusivo de este continente (Preston, 1999). Esto muestra, al menos en una primera lectura, un enorme éxito del proyecto NL, no solo entendido como "doctrina" sino como “programa de acción” y “transformación” (Bulmer-Thomas, 1996; Solimano, 1998).

El mercado se hizo más importante: como forma de regulación económica y social, como vía y modalidad para buscar mejores condiciones de vida y acceso al consumo, como sendero para intentar integración social. El mercado se hace más el centro de gravedad de la sociedad y de la vida; ésta depende más de tener capacidad de compra y, para ello, de tener algo que sea vendible. Las instituciones de la sociedad que se fueron creando permitieron y alentaron que la iniciativa empresarial y el capital privado pudiesen

\footnotetext{
${ }^{15}$ La teoría económica neoclásica y sus desarrollos y ampliaciones posteriores, base conceptual del programa NL, sobrevivió y se puede decir que gozó de cierta buena salud en el siglo XX a pesar de un conjunto importante de embates que tuvo durante dicho siglo; entre estos: i) las teorías de la competencia imperfecta y la existencia de mercados oligopólicos; ii) el keynesianismo y post-keynesianismo y la imposibilidad de la autorregulación mercantil sin crisis y desempleo; iii) el "schumpeterismo y su énfasis en los desequilibrios más que en los equilibrios en la dinámica económica; iv) el desarrollismo con su énfasis en la necesaria acción estatal como impulsor de procesos de despegue; v) el ecologismo y la no equivalencia entre los precios y los costos sociales de la actividad productiva, entre los más importantes. Esto al margen de las críticas provenientes del marxismo sustentadas en la teoría de la plusvalía como base de la ganancia (explotación económica) y las crisis inherentes de sobre-producción del sistema capitalista mercantil.
} 
“colonizar" nuevas áreas de actividad: educación, salud, agua, pesca, bienes ambientales, seguridad social. Ha existido en América Latina, una mercantilización de la sociedad rompiendo limitaciones que había generado el siglo $\mathrm{XX}^{16}$.

El NL disminuyó el papel de la política democrática y la acción colectiva como vías de construcción del orden socio-económico (Garretón, 2012: 23-37). La política se vilipendió y se asimiló a un orden técnico -sustentado en la economía como ciencia exacta- y de respuestas únicas, sin connotaciones ideológicas ni afiliación respecto de los intereses y la mirada de ciertos grupos sociales. Los economistas NL se constituyeron en un agente vanguardia de esa ideología cientificista. ${ }^{17}$

Ese orden mercantil acrecentado se acompañó de la privatización de los activos y de la riqueza en América Latina, antesala clave, a la vez, de la diferenciación de ingresos que comenzó a ocurrir. Un enorme patrimonio público o estatal pasó a propiedad privada en las últimas décadas; revolución patrimonial que no encuentra parangón en la historia independiente del continente y que queda bien expresada en la noción de "acumulación por desposesión" de David Harvey. ${ }^{18}$ El proceso privatización-mercantilización expresa fácticamente un éxito NL sin precedentes en la creación de un nuevo orden socio-económico. Esto estuvo ligado, componiendo una "trinidad", a la transnacionalización de la economía. La privatización ocurre, como nunca, ligada a procesos de transnacionalización que son mayores y más amplios -importantes en el sector de servicios- que los ocurridos en los años 50 y 60 durante la industrialización y que habían llamado la atención y discusión en esos años. También, esta vez, la inversión extranjera se expresa en la compra de tierra, sobre todo en la última década ${ }^{19}$ (Gutierrez, 2006).

Con todo ello, el continente se hace más parte del mundo globalizado -aunque, en condición más periférica- con decisiva presencia de agentes que operan a esa escala. ${ }^{20}$ Es esto un nuevo éxito del NL,

\footnotetext{
${ }^{16}$ Que mostraba, a su vez, que el grado de mercantilización de la sociedad no es un proceso evolutivo lineal, incontenible, sino ha sido un campo de disputa histórico, más allá que la modernización capitalista, en un sentido amplio, se caracterice por una ampliación de lo mercantil. Ello fue mayor en Chile pues su neoliberalismo precoz y radical conto con una fuerte represión y control en su fase más inicial y luego generó más chorreo -aunque muy desigual- de ingresos sobre la sociedad, permitiendo avances en contextos más democráticos.

${ }^{17}$ Presentándose como reconstruyendo o refundando una economía que correspondía a una ciencia y técnica no sujetas a la evaluación de los no especialistas (no economistas liberales) situando la política económica "totalmente fuera del alcance de los grupos de intereses, de los legisladores y de la población (...) era a la vez legítimo y necesario" (Conaghan y Malloy, 1997: 878).

${ }^{18}$ Chile aquí nuevamente juega un papel de líder. En la segunda mitad de los 80, luego de la crisis -y que algunos economistas lo han denominado de NL pragmático, en oposición al NL ortodoxo de una primera etapa- se revela, sin embargo, que alrededor del $15 \%$ del valor del PIB se privatiza. Más que todo el período de Margaret Thatcher en el Reino Unido (González Meyer, 2004).

${ }^{19}$ En África, la compra de tierras por empresas extranjeras fue desde unas décadas anterior y cubre una cantidad de tierras varias veces mayor.

${ }^{20}$ Un país como Chile pasa del 0 al 70\% de exportación privada de cobre -entre 1973 y 2016- y de esta cerca del 95\% es por parte de empresas trasnacionales. Argentina pasó de 34 a 50\% de exportaciones trasnacionales.
} 
que siempre leyó esa transnacionalización no como signo de pérdida de soberanía, sino como de mundialización y, más específicamente, como confianza en los capitales extranjeros, reconceptualizados como condición básica del crecimiento, entendido como desarrollo. Esa mundialización o globalización va acompañaba de la apertura de las fronteras a los flujos financieros para su desplazamiento libre por el continente, en función de sus cálculos y estrategias.

En las direcciones anteriores, el NL logra orientar y unificar a capas amplias del empresariado y de las elites conservadoras. No aparecieron con fuerza fracciones empresariales con algún proyecto de desarrollo nacional proteccionista y pro estatales. El NL agrupó a sectores empresariales que tenían distancia no solo del socialismo sino también del "capitalismo estado-céntrico" (que daba demasiado poder, según situaciones, a políticos, tecnócratas y militares). Las empresas medianas y pequeñas no fueron la base de alguna fuerza alternativa dentro del capitalismo. Así, en parte, la hegemonía del NL se percibe en el éxito de formar al agente que deseaba para encabezar el proceso de desarrollo capitalista liberal. Al menos, lo reforzó y debilitó a otros.

Este cuadro descrito termina, en un balance general, estructurando un tipo de relación con la economía mundial que repitió y acentuó la secular inserción latinoamericana vía sus "ventajas comparativas" asimiladas a las ventajas naturales. Pero esto no debe ser entendido, dentro de la lógica NL, como un fracaso, sino como algo que expresaba que era justamente allí donde estaban las ventajas latinoamericanas de cara al mundo. ${ }^{21}$

En síntesis, el NL estableció marcas claves de la anatomía y fisiología económica de A.L. y, desde allí, en la sociedad en general. Con ello quiero decir que "la trayectoria" de A.L. tuvo una desviación -en el sentido de un nuevo trayecto que queda como una marca en su historia. El significado más profundo de esa "desviación" lo podemos visualizar si recordamos las circunstancias históricas en que emergió el NL: las "reformas estructurales liberales" (Salama, 1999) fueron un tipo de salida específico a los dilemas y conflictos históricos que fueron cristalizando durante el intento de industrialización entre los años 30 y 80. Proceso que había generado, constitutivamente, conflictos, impases, "cuellos de botella” y opciones o

\footnotetext{
${ }^{21}$ José Piñera dijo de Chile que es un país con mercado pequeño pero provisto de cuantiosos productos de origen minero, agrícola, pesquero y forestal, por lo que las ventajas del intercambio internacional son enormes, agregando que durante los cuarenta años anteriores al NL "se desconoció este hecho fundamental" (Devés, 1993: 284).
} 
propuestas de tipo anticapitalistas, socialistas, nacional-populares. Ello es lo que constituye el éxito mayor del NL o, si se prefiere, de los agentes que lo implantaron: el desplazamiento de otros caminos (y agentes) alternativos, en dos sentidos: primero, en un sentido fáctico, material, de ubicarse "en vez de", "en alternativa a"; segundo, en un sentido imaginario, pues la propia instalación del NL, del escenario reajustado -y más allá del control o represión de los casos- hizo menos posible la constitución de fuerzas que siguieran sosteniendo aquellas otras alternativas. Fue un desplazamiento "en el presente" y "hacia el futuro". Dentro de ese significado histórico, implicó en lo más esencial, retomar la defensa y seguridad de la propiedad privada que era común a los modelos antisocialistas o anti nacional-populares. Eso compensó a algunos actores perjudicados con la no prosecución del ideario industrialista, así como con el antiestatismo frente a un Estado que comenzaba a ser peligroso más allá de ciertos límites (Conaghan y Malloy: 1997).

En interacción con la instalación de esa nueva anatomía y fisiología, el NL fue clavando ciertas banderas ideológicas que permitían justificar lo ya instalado, ampliando los senderos para su consolidación como "modo de ser y reproducción" socio-económico. Era una ideología del orden y estabilidad económicos; de la empresarialidad, las oportunidades y del esfuerzo propio; de lo inconducente de organizaciones, reclamos, presiones. Todo ello -en grado bastante directo y dependiente al tipo de resultados económicos que se iban obteniendo- fue ganando adeptos hasta fines de los años 90, e influyó, paralizó o convirtió a significativos sectores políticos e intelectuales leídos como "progresistas", mostrándose, como una alternativa cuasi única de desarrollo (Souza Santos, 2014: 75-97). Esto, por supuesto, dentro de un proceso mucho más vasto, que a partir de cierto momento contó a su favor con la fuerte derrota y descredito de las experiencias socialistas, en buena parte donde estaban implantadas, junto al debilitamiento o sencillamente extinción, como "modelo" de referencia, de las que quedaron vivas (por lo menos así autodefinidas: China, Vietnam, Cuba y Corea del Norte).

Emergen, además, "nuevos mapas cognitivos y valorativos referentes al estado, la economía, la libertad, la justicia social, a los papeles y relaciones deseables entre el estado, la economía y los individuos". Hay inflexiones, también en expresiones del mundo popular más comunitario hacia comportamientos más liberales, individualistas y competitivos. Asimismo, en segmentos significativos de las elites y clases medias se propagaron con éxito "valores anti-estatistas relativamente fuertes, debilitando la legitimidad 
de las instituciones públicas decisivas para el mantenimiento y la expansión de la cohesión social" (Conaghan y Malloy, 1997).

Sin embargo, lo anterior no ha sido toda la realidad. La instalación y grados de adhesión al NL no se escribieron sobre tierra "descampada", sin historia, y sin resistencias. De partida, la orientación NL en varios países se hizo -se tuvo que hacer- bajo estados dictatoriales, con represión de liderazgos políticos y sociales y con un fuerte control de cualquier expresión crítica. En otros casos, se aplicó por autoridades que habían salido elegidos con programas socio-económicos distintos y que fueron la base de reacciones sociales posteriores levantando liderazgos alternativos (como Venezuela, Ecuador, Argentina, Bolivia, Perú). Incluso se tuvo que apelar a garantías constitucionales desde los ejecutivos para ahogar reacciones de sectores sociales por los efectos de políticas económicas NL. El NL no surge, en la mayoría de los casos, desde claras plataformas políticas y programáticas sostenidos por candidatos a las presidencias; sino que luego se imponen "desde arriba" subordinando a los congresos e ignorando a la sociedad civil. (Conaghan y Malloy, 1997).

Eso era muestra de la existencia, en el continente, de ideologías y sentidos comunes construidos y heredados que era necesario neutralizar, silenciar o contornear, pero que no fueron vencidos, plenamente, en el terreno de la deliberación democrática, aunque sus discursos alternativos se debilitasen. El NL tenía limitaciones en cuanto a representatividad pues su instalación significaba costos altos para clases medias y populares (aumento precios, congelamiento de salarios, disminución empleo estatal). También conflictos con algunos de los componentes de una alianza empresarial pro-mercado, en tanto eran directamente afectados por las medidas. Constituía una tensión entre la teoría y la práctica y una suerte de “parto de la transición”. Así, su avance estuvo sostenido en un núcleo duro como los tecnócratas, NL locales, instituciones internacionales NL y las grandes empresas nacionales/extranjeras exportadoras, junto a las empresas trasnacionales. Así el NL tuvo más éxito en articular a las elites que a las elites y las masas. El NL no parecía ser la vía para generar una estabilidad sólida, a través de la cual pudiesen encontrar representación los diferentes grupos, clases, tradicionales y emergentes,

En ese escenario, el terreno del consumo fue clave a definir la fortaleza o debilidad de la instalación NL. Hubo momentos en que este se expandió, multiplicándose la cantidad de artefactos/mercancías al alcance de los consumidores; en que se abrió (democratizó) el crédito; en que entre las masas se diversificó el 
acceso a la variedad, a los colores, a las formas, y se constituyeron polis más mercantiles. Pero también llevó, permanentemente, la amenaza del descontento cuando esos procesos se angostaban por coyunturas internacionales y/o políticas nacionales y se hacía visible la enorme desigualdad que el proceso llevaba. ${ }^{22}$ Esos momentos críticos se acompañaban de la denuncia de rasgos del NL que lo desprestigiaban, como su promoción de la especulación financiera y su lejanía real de la recompensa al esfuerzo propio.

Producto de esas tensiones, podemos afirmar, al menos como hipótesis plausible, que la privatización y mercantilización instaladas y el significado cultural del aumento de la posesión de bienes privados, no extinguieron una cierta conciencia de lo público. Ciertos problemas o temas se siguieron (y siguen) representando, no como el resultado de una pura relación entre privados en el espacio del mercado sino como elementos constituyentes de lo público y que dan fundamentos a la acción política, como serían la educación, salud, alimentación, medio ambiente, seguridad social, vivienda, etc. Algunos conflictos que se levantaron en algunos países, a veces atravesando fronteras nacionales son su reflejo, como es el caso de la movilización del agua en Cochabamba, situaciones de contaminación y degradación ambiental en varios países, la educación en Chile. En estas reacciones se actualizan antiguas ideas construidas en las luchas sociales del siglo XX, que constituyeron representaciones de los derechos y del rol público, pero, a la vez, expresan nuevos objetos de conflictos que toman fuerte cariz público, como el ecológicoambiental.

Lo recién señalado constituyó un límite importante a la "utopía" NL de la eliminación de la política y la acción colectiva, de manera de dejar libre al mercado para la regulación económico-social. La sociedad experimenta malestares ante grados de mercantilización excesiva que, a la vez, se experimentan no como un terreno de relaciones neutrales, equitativas, sino también de poderes en que, con facilidad "el grande se come o somete al chico" o "este se somete al primero". Posiblemente es el descrédito de la política en algunos países, vista como esfera de reproducción de las mismas elites, lo que impide una politización mayor de esas experiencias o, como veremos, la aparición de alternativas por sobre o al margen de la institucionalidad convencional.

\footnotetext{
${ }^{22}$ En el marco de este tipo de análisis debiésemos entender el enorme significado de la expansión asiática de la segunda mitad del siglo XX que permitió - sobre la base de costos menores, de una alta productividad, y de la generación de sobre-producción mundial en ciertas mercancías- el acceso abaratado por vías formales e informales a múltiples mercancías privadas que simbolizaron un sentido de "estar modernizándose" o "estar progresando" en variados lugares del mundo y de América Latina. Esas mercancías privadas (electrónicas, por ejemplo) superaron a bienes públicos, en su capacidad de simbolizar "el sentido y la vivencia de modernidad".
} 
Podríamos afirmar que, desde una perspectiva histórica, la modernización socio-económica NL -esto es, un "neo-desarrollismo" con protagonismo de lo privado, trasnacional y mercantil- que aquel se propuso, no generó de manera sólida una formación socio-económica con alta capacidad de integración social que pudiese actuar de base de una reproducción estable del sistema, dentro de una temporalidad de mediano plazo. Ello suponía algún grado importante de éxito en dar respuesta a objetivos de desarrollo, bienestar, oportunidades. En ese sentido amplio, y en una escala continental, el NL no aparece exitoso ni "objetiva" ni “subjetivamente". Problemas seculares de exclusión, con pobreza y brechas impresionantes de desigualdad, continuaron reproduciéndose (Figueroa y Cordero: 2011). A la vez, el programa NL no logró establecer una hegemonía clara en el grupo del "sector informal urbano", al cual intentó dotar de un discurso neo-schumpeteriano, pero que sigue siendo un grupo poco adscrito de manera sólida a cierta visión especifica.

Por otro lado, la expansión exportadora perpetuó a América latina como rentista de la naturaleza (“extractivista") como había adelantado la corriente neoestructuralista (Burchardt, 2006). En la medida que primaria, esta exportación, como era previsible, no construyó densas y articuladas cadenas con integración de pequeños y micro empresarios. Con ello reprodujo la secular heterogeneidad estructural que ha acompañado la historia económica de A. Latina. Siguió exponiendo las economías a las fluctuaciones de los precios de los productos primarios y a las oleadas de capital productivo y financiero, en contradicción con su enfatizada búsqueda de estabilidad macro-económica, como condición de una economía sana. A la vez, América latina no se transforma en un centro de conocimiento de los recursos naturales, marcando su ciencia y tecnología, sino que esto sigue concentrándose en grandes empresas trasnacionales y sus países de origen ${ }^{23}$. A la vez, la mayor inserción internacional y una orientación más importante hacia los mercados externos, se hizo basada en una importante desigualdad interna (Salama, 1999).

También, en varios países, se han levantado movimientos indígenas y campesinos por la tierra, que han reaccionado a los programas NL. La re-primarización de las estructuras productivas están a la base de la relevancia que han cobrado conflictos, que se combinan con movimientos ciudadanos centrados en la

\footnotetext{
${ }^{23}$ Debe sí destacarse un fenómeno que se desarrolla bajo el NL con mayor fuerza que antes cual es el de grados de industrialización periféricos del tipo "maquila"; es decir con base a la deslocalización de empresas globales y la subcontratación de trabajadores. Esto, en la medida que sucede, además de México, en varios países centroamericanos, hace crecer ese tipo de industrias en dichos países, mientras en el cono sur del continente, en varios países, históricamente más industriales, ocurrían grados de des-industrialización.
} 
defensa de recursos naturales, como el agua, la biodiversidad y la calidad del medio ambiente, crecientemente definidos como bienes comunes. El NL muestra imposibilidades para aproximarse a "lo étnico", por su carácter anglocéntrico y su naturaleza reacia a todo aquello que significa agrupamiento, expresión colectiva e interventor potencial sobre el mercado. A la vez, reacio a toda expresión que posea, aun cuando sea parcialmente, lógicas no mercantiles, oponiéndose a un universalismo liberal, desde bases culturales propias, como la reciprocidad, el comunitarismo, y las relaciones no mercantiles con la naturaleza (Martínez Allier, 2005).

En esa conjunción y terreno de "modos heredados de ser" y de la necesidad de defenderse frente a impactos sociales negativos se recupera y en gran medida se actualiza un lugar y sentido del quehacer del Estado y el aumento de presiones para que actúe en el sentido de un mayor equilibrio social. Aun desde las filas de las instituciones impulsoras mayores del NL, como el Banco Mundial -en discusión con el FMI (Stiglitz, 2002) - se levantan, desde fines de los años 90 del siglo XX, el reconocimiento de la importancia de un mayor rol estatal en la economía frente a peligrosas desintegraciones sociales provocadas por la liberalización de las economías, que terminaran viéndose como peligrosos problemas de gobernabilidad. Se afirmará desde ese lugar, una especie de "neo-neoliberalismo" o liberalismo moderado (González Meyer, 2013). Del Estado entendido como “el” problema, se pasa a concebirlo como parte de la búsqueda de soluciones, aunque insistiéndose que debe ser un robustecimiento amigable con el mercado o directamente "pro-mercado". ${ }^{24}$ Esto es llevado más lejos por visiones directamente críticas al NL, generándose una atmosfera que repone viejas proposiciones ligadas, aunque vagamente, sea al Estado Bienestar o al Estado Desarrollista.

Esos elementos permiten afirmar cierta debilidad o resquebrajamiento hegemónicos por parte del NL. (Figueroa y Cordero, 2011). Podríamos avanzar a la afirmación que la instalación del NL en la sociedad latinoamericana no tuvo un soporte socio-cultural que tuviese el mismo grosor o peso que el de su instalación “de hecho". Expresado de otro modo: la monumentalidad de la reestructuración socioeconómica de América Latina por la orientación NL, no tuvo un equivalente en un sentido común y un convencimiento de buena parte de la población. Se apoya en grados diversos, pero significativos, en un consenso pasivo (Gramcsi) y en una "hegemonía fáctica", entendida ésta como un orden que produce

\footnotetext{
${ }^{24}$ Una serie de nociones se popularizarán dentro de los medios oficiales internacionales y nacionales y que serán resumidos en la idea de "modernización del Estado" que significa que esté más presente, que sea más eficiente, que actúe frente a las "fallas de mercado", pero que ello sea sin crecer. Es la idea, entre economistas y políticos, de un Estado, más que grande, "musculoso" (Stiglitz, 2002).
} 
disgusto pero que resulta difícil alterar en sus reglas de funcionamiento. Así, la economía y la sociedad son más NL que lo que la misma sociedad desea, lo que abre al malestar, pero no necesariamente a la propuesta. Brecha que también expresa lo que se ha popularizado como los efectos de la "doctrina del shock" y que hace referencia a una parálisis social constituida a partir de un evento traumático. ${ }^{25}$ Aunque no pueden establecerse ligazones totalmente directas, lineales ni unicausales, el NL crea condiciones para el aumento de la delincuencia, grupos mafiosos, lo que llega a copar zonas y a veces debilitando otras lógicas de acción del mundo popular.

Sin embargo, ese poder más factico que hegemónico en el sentido gramcsiano, no debe ser mirado con desdén o expresión de pura debilidad. Es justamente la fuerza de esa "facticidad", de ese modo y escenario material de funcionamiento, de esas estructuras de poder, que lo expresan y lo sostienen, lo que hace difícil el surgimiento y el sostén de alternativas profundas al NL.

\section{¿Gobiernos y escenarios postneoliberales?: emergencia de un tiempo en redirección}

Atmosferas y acciones post NL

En el contexto NL relatado, de dominaciones y resistencias parciales, de elevado poder fáctico y de aumento de contestaciones organizadas, emergieron en América. Latina un amplio grupo de gobiernos de centro izquierda desde la primera década del nuevo milenio (Buendía, Mateo, y otros, 2013; Déniz, de León y Palazuelos, 2011). Esto pareció reforzar fuerzas y tendencias hacia un post-neoliberalismo, aunque, desde su nacimiento ese fenómeno despertó juicios encontrados. Fueron caracterizados, indistintamente, como una simple continuidad de las políticas y una nueva cara del NL en América Latina; una corrección del NL integrándole una cara más social; el retorno del Estado a la economía después de su exclusión bajo el NL; un nuevo ciclo de populismo en América Latina que conduciría a romper la razonabilidad de la política económica ganada en los últimos decenios en el continente; la emergencia y significativo avance hacia un proyecto alternativo al NL, sustentado en nuevos pilares como el nacionalismo económico, los intereses de las clases populares, o la renovada consideración y participación de los grupos indígenas, etc. Estos juicios tan disimiles correspondían principalmente a las ideologías previas de sus emisores, pero también recogieron algo real de la mixtura y tensión que ha estado presente en (y entre) aquellos gobiernos o en los movimientos que los apoyan.

\footnotetext{
${ }^{25}$ De todas formas, me aparto relativamente de la visión implícita de la "doctrina del shock" por su simpleza, su mirada poco compleja de la acción individual y social; como especies de cuerpos o agregados vacíos donde se introduce fácilmente cualquier mensaje. Son personajes sin historia, personajes en blanco, donde se instala con extrema facilidad la escritura y el interés del poderoso.
} 
Mirados como conjunto y en sus propias singularidades, los procesos socio-económicos dirigidos por dichos gobiernos no son fáciles de caracterizar y han representado más un movimiento disperso y muy asociado a singularidades nacionales que a una cristalización común y madurada, aunque sí con la discursividad común de fuerte crítica al NL. En algunos casos se levantaron ideas que enunciaron un proyecto o propósitos amplios de cambio, dentro del cual se inscribirían las políticas específicas, pero sometidas a impulsos, vaivenes y contradicciones surgidas de los propios procesos nacionales: "socialismo del siglo XXI", "buen (con)vivir", "revolución ciudadana”, re-industrialización nacional, según países (Moreira, Raus y Gómez, s/f). Estos procesos tuvieron, junto a sus basamentos socio-estructurales de reacción al NL y de cierta movilización social que les dio vida, una influencia significativa de líderes que fueron importantes para lograr representar, articular y movilizar fuerzas y descontentos. El lugar de personajes como Chávez, Morales, Correa, Lula, Ortega, Kirchner-Fernández, aunque diferentes entre sí (y en sus desenlaces), fue significativo en la dinámica social (Déniz, de León y Palazuelos, 2011).

Con cautela, se puede decir que son identificables algunas direccionalidades en las conducciones latinoamericanas que podemos entender como introducciones a un post-neoliberalismo que se extendió en el continente. Sin embargo, es importante distinguir entre programas o ideas de gobierno y las orientaciones efectivas luego existentes (Ospina, 2012), así también entre discursos y políticas efectivas. Con todo, y aceptando elementos de retórica, se debiese reconocer que, como conjunto y más allá de sus diferencias, han generado un ethos discursivo y algunas políticas, en buena parte de América Latina, que colaboraron para abrir de manera extendida la imaginación a nuevos trayectos, que podrán en un futuro, ser evaluados como creadores de bases de un nuevo orden post-neoliberal, como un impulso abortado por fuerzas más poderosas, o como proyectos auto abandonados.

En el terreno preciso de su caracterización es acertado decir que en cierto grado estos gobiernos han representado una profundización de la línea de un NL moderado, antes señalado, a diferencia de un liberalismo económico mucho radical (FMI) (Stiglitz, 2002). Esto significaba una valorización de la acción política como interventora en los procesos económicos, concediéndole una mayor legitimidad al Estado en su responsabilidad explicita en el desarrollo y bienestar. Esto lleva a cuestiones e iniciativas que se sitúan fuera de los márgenes en que se había desenvuelto el NL y que crea un escenario más postneoliberal, como por ejemplo, la importancia que cobró para los “nuevos” gobiernos la cuestión de una 
apropiación y distribución más estatal de la renta de los recursos naturales. ${ }^{26} \mathrm{El}$ caso más paradigmático fue el boliviano, con los hidrocarburos, en que se produce una transformación entre la parte del excedente que se llevaban las empresas extranjeras y las que quedaban para el Estado boliviano (Molero y Paz, 2013). También estuvo en el caso argentino con los impuestos a la exportación de Soya. La disputa por la apropiación de esa renta pasó a ser, entonces, clave para Estados que querían ser más protagónicos en el desarrollo y la distribución.

Esta acción más protagónica del Estado, es entendida como aquella que debe basarse en grados y en formas de organización, movilización, adhesión y presencia popular, sin lo cual no tiene posibilidades de éxito. Esto significa que, finalmente, los Estados suelen tomar vínculos privilegiados con partes de la sociedad más afines, interviniendo en sus pesos internos. Con esto, la política y la acción social se alejan de ser percibidas, a la manera NL, como esencialmente distorsionadoras del mercado, entendido este como integrador y regulador óptimo de la sociedad. Esto, sin embargo, se realiza con grados de cautela en términos de que no conduzcan a propuestas o presiones distribucionistas demasiado fuertes que pudiesen conducir a desequilibrios económicos instalados fuertemente en el imaginario político como desestabilizantes, por el persistente discurso NL, pero también por las experiencias latinoamericanas de hiperinflaciones.

Esta etapa de gobiernos “post-neoliberales" puede caracterizarse también por una mayor consideración de "lo social" en el desarrollo. El avance en esta dimensión deja de ser vista como la resultante natural de un proceso de crecimiento económico que "chorrea" hacia el conjunto de la sociedad, más algunas políticas sociales hacia la "extrema pobreza", aunque ello no lleva de manera extendida a fijar salarios o precios de bienes y servicios de consumo popular. Esta consideración más expresa de lo social, es acompañada de un discurso que reintroduce más visiblemente los derechos sociales y hace más presente el propósito de la "inclusión" social. Ello se expresa en una clara mayor magnitud de recursos orientada a programas sociales., así como a la creación de ellos, como la "Ley de protección social y desarrollo comunitario" o el proyecto de reforma de ley de pensiones (sistema de seguridad social), en Bolivia o los programas de Lula en el Nordeste (Buendía, Mateo y otros, 2013).

\footnotetext{
${ }^{26}$ La renta basada en los recursos naturales es un excedente (diferencia entre ingresos y costos) que no se genera a través o a partir de inversiones o del trabajo (aunque se les necesite); que no requiere continua reinversión como en general en la renta capitalista pues está sustentada mayormente en la calidad del "recurso natural" que se posee y se explota. La apropiación y distribución de esa renta está sometida a razones políticas, aunque, naturalmente, de fuerte raíz económica.
} 
En buena medida, los programas se han financiado con los mayores recursos del Estado proveniente de buenos precios de los productos primarios que se exportan y de las negociaciones que han permitido aumentar la participación de los Estados en esas ganancias. En este sentido, se pudiese caracterizar esta orientación post NL, como el pasaje hacia un rentismo más social y más democrático, dando origen al fenómeno del neo-extractivismo. Sin embargo, esta mayor acción social, no se logra convertir en una nueva idea de "Estado Social" renovado y alternativo a las ideas de la subsidiariedad y de la focalización que predominó en los programas NL. No está claro si es una ampliación de ese carácter subsidiario, un intento de avanzar o retornar la idea de los estados de bienestar constituidos en el siglo XX, o una idea nueva.

En parte conectado con el discurso de un desarrollo más social, los nuevos gobiernos plantearán las necesidades de apoyo a la producción de pequeña escala, como los programas en Ecuador y también en Argentina, surgiendo una política hacia una pequeña agricultura familiar. Se le dio, también, una consideración más relevante, registrada en nuevas constituciones, a formas de propiedad y gestión económicas, diferentes a la privada capitalista y a la pública estatal, que prefigura un "modelo plural" de economía, como es el caso de Bolivia. Ello no solo releva, en términos del proyecto socio-económico a reconstruir, propiedad y gestión públicas, cuestión natural, sino también al sector cooperativo, asociativo, solidario o comunitario de la economía, como un tercer y cuarto sector, lo que, en este último caso, comprende las prácticas productivas y de organización económica de los pueblos indígenas (Loza, 2016; Jiménez, 2016; Vázquez, 2016).

Con relación a lo anterior, se ha dado un mayor reconocimiento a los pueblos indígenas. Esto significa el reconocerse como realidades plurinacionales que deben aceptar derechos a autonomías territoriales a pueblos indígenas para tener sus propias modalidades de organización económica, pero también, y junto a ello, para reproducir su cultura y tener fórmulas de autogobierno. El año 2010, en Ecuador, hubo "saneamiento" de 56 millones de hectáreas de un total de 107, y 20 millones de hectáreas pasarían a distribuirse en los pueblos indígenas originarios y campesinos. Ello se plantea como acceso equitativo de la tierra mediante el fortalecimiento de los programas de dotación y titulación. Asimismo, a partir de un referéndum quedo definido oficialmente como un País Plurinacional y Multiétnico. En la Constitución y como proceso cultural, subyace una influencia del indigenismo en aspectos relacionados con la 
significación dada a la tierra y a los recursos naturales y en maneras de concebir el modelo económico existente.

Detrás de la mayor apropiación y uso de la renta por parte del Estado, otra característica es un cierto nacionalismo socio-económico que retoma la defensa de la propiedad o usufructo de los productos naturales por parte del Estado; aunque esto, en general, no se extiende hacia el resto de la economía. Ecuador de Correa renegoció la deuda externa, realizó una revisión de los contratos con las empresas petroleras, generando un aumento significativo de la recaudación tributaria. Además, se normó la ilegalidad de la deuda externa y prohibió los contratos con arbitraje internacional, para fortalecer las decisiones internas nivel país. En Argentina, se limitó la propiedad extranjera máxima de la tierra el año 2011, aunque no es claro que ello haya sido efectivamente fiscalizado (Palazuelos y Villarreal, 2011).

Este mayor nacionalismo en torno a los productos primarios suele acompañarse de un planteamiento, ausente bajo el NL, de una industrialización entendida como agregación de valor interno a dichos recursos o una industrialización más clásica, por ejemplo en Argentina. ${ }^{27}$ Esta visión más industrialista, suele formularse en términos de contradicciones con el NL: economía real versus economía financiera; industria interna versus las exportaciones primarias; inversión nacional vs capital extranjero; mercado interno versus mercado global; Estado versus sector privado/mercado. Sin embargo, ello no alcanza a tomar la forma de un claro proyecto de desarrollo con nuevos agentes protagónicos. Esto solía enunciarse como cambio en la matriz productiva que sacara a los países del extractivismo e introdujese una mayor diversificación productiva (Ospina, 2012).

En ese marco de discusión se levanta de manera tenue un ideario antiextractivista que recuerda, una vez más, el patrón débil de desarrollo económico y social que genera una pura estrategia de apertura económica y comercial, con protagonismo de agentes externos o nacionales, y que hace depender excesivamente del precio y demanda de los productos primarios. Este planteamiento de una mayor industrialización interna, más el "social" antes señalado, es otro que ha llevado a la introducción de un cierto post NL, al buscar apoderarse de una mayor renta de recursos naturales que permita promover

\footnotetext{
${ }^{27}$ En este sentido retoman algo central del planteamiento neoestructuralista (cepaliano) de fines de los años 80 y desarrollado en la década de los 90, cuyo autor inicial es Fernando Fanjzilber. Ese planteamiento sostiene la necesidad de escapar, con una acción participativa del Estado -en ciencia y tecnología, en infraestructura, en educación, en pequeña y mediana empresa, en equilibrios sociales- a una especialización primaria de América. Latina que sería a lo que conduciría una apertura al mundo solo en manos de la empresa privada y de acuerdo a la regulación del solo mercado.
} 
aquella industrialización. Ello permitiría generar un proyecto nacional cautelado por una presencia activa del Estado, que generaría una dirección del proyecto de ruptura con el NL. Sin embargo, críticamente se le ha calificado de neoextractivismo por el uso más social del excedente capturado por el Estado pero que no logra transformar la matriz productiva (Svampa, 2016).

Por último, podemos caracterizar a estos gobiernos como unos que han intentado diversificar las relaciones económicas internacionales, escapando de los Estados Unidos de Norteamérica y de organismos internacionales fuertemente influidos por las visiones favorables a dicha nación. Eso se ha expresado en la búsqueda de fortalecer relaciones económicas y políticas con países como China y Rusia; asimismo, del endeudamiento con organismos financieros internacionales como el FMI, que ha sido la base desde la cual dicho organismo presiona por políticas de marcado acento NL.

Alcances, límites y balances de las orientaciones post NL

El espacio-tiempo contingente -visto desde la historia larga del continente, de la incrustación del NL y de las fuerzas reactivas recientes- muestra una mayor hibridez entre lo estrictamente NL que ha permanecido y los nuevos elementos que han sido introducidos. Un ejemplo son las nuevas constituciones latinoamericanas que expresaron la entrada y marca de nuevas prácticas, ideologías e intereses, según países: formas de propiedad asociativa; reconocimiento de "sujetos" en la escena pública (pueblos indígenas), derechos de la naturaleza (Ecuador), socialización de la previsión, formas más equilibradas de negociación salarial (Uruguay), políticas de inclusión social. Podemos hablar de un debilitamiento del NL que, sin embargo, no es lineal sino con contra-ataques como en Argentina y Brasil (Buendía, Mateo y otros, 2013). En algunos casos, la reacción liberal suele asumir alguna parte de las críticas al NL, como forma de legitimación; sin lograr cerrar la puerta a la expansión de esas críticas ni a que estas resbalen hacia el imaginario de un orden social distinto.

Es un tiempo "fangoso", en que no es fácil el desplazamiento societal decidido hacia una otra situación: ni a la reversión hacia un NL más ortodoxo ni al avance frontal hacia un post NL. Es un impasse donde fuerzas y aspectos críticos a la reproducción del NL han ganado lugar y lo han ido debilitando; pero en que las fuerzas, claridades y posibilidades de producir ese otro “orden post-neoliberal” son insuficientes. Así, muchas políticas específicas van a adquirir su pleno significado según hacia donde se oriente el aún incierto movimiento general de los países. El terreno fangoso hace difícil un desplazamiento largo en un 
sentido u otro. Los vientos no soplan en una dirección dominante y la realidad se hunde en ese terreno en una disputa de fuerzas y sentidos.

Más allá de la hibridez y fangosidad, la evaluación de la situación a contraluz de la emergencia de movimientos, expresiones y gobiernos críticos al NL, pareciera ser de una cierta frustración respecto de la construcción de un orden socio-económico post NL, que se dibujó hace poco más de una década y media. Tomando el ciclo de "gobiernos progresistas" podríamos decir que los anuncios revolucionarios están por encima de las realizaciones. Para algunos esto no es solo que los gobiernos fueron más lentos de lo esperado, sino que se debilitó el proyecto y la orientación de los cambios (Ospina, 2012). La realidad parece asimilarse a un galope frustrado desde el punto de vista del objetivo de un cambio social hacia un nítido post NL. Este fracaso se expresa en relación a un conjunto de nudos críticos que quedan instalados como puntos de mira y análisis respecto de los desafíos - no resueltos-de un cambio social continental.

América Latina no logró la superación del extractivismo y revertir la "reprimarización" del tiempo NL con su tendencia a la sobre-explotación de los recursos naturales. Esto, a pesar de la acumulación de una fuerza ideológica y política crítica de dicha primarización, proveniente de vertientes desarrollistas clásicas, nacionalistas, ecologistas, liberales pragmáticas y socialistas tradicionales. No se alteró el escenario de los megaproyectos en la minería, y del acaparamiento de tierras y expansión de las fronteras agrarias, forestales y monocultivos. No emergió una experiencia práctica de desarrollo (o post-desarrollo) alternativo al extractivismo. Lo que sí se produjo es una mayor participación estatal en la renta de los recursos naturales y su uso dirigido a políticas sociales hacia grupos pobres e infraestructura, lo que ha sido caracterizado críticamente como "neoextractivismo", como continuación de deterioros ambientales e impactos desestructurantes en los territorios.

Esta denuncia del "neoextractivismo" ha sido la base de un discurso crítico a las estrategias que se pretenden anti NL en el continente y ha constituido un concepto con importante capacidad interpeladora para mostrar los límites de políticas enunciadas como transformadoras. Esta debilidad se hizo más patente en los años más recientes en que se experimenta esa dependencia al caer los precios. Además, en la segunda mitad del segundo decenio del presente siglo se ha mostrado la clásica debilidad de esa dependencia al caer el ciclo expansivo de los precios de los commodities y obligar a ajustes socioeconómicos internos. 
Umbilicalmente unido con lo recientemente dicho, no se ha avanzado en la generación de otra matriz productiva que desplace ese carácter exportador primario criticado. Hubo nociones que surgieron para expresar ese propósito, en varios países: núcleos endógenos de acumulación en Venezuela, el paso a la bío-producción en Ecuador; la reindustrialización en Argentina; el valor agregado nacional en Bolivia. Se habló, en algunos casos, de fases de esa transición (Ecuador). Sin embargo, no logró desarrollarse una orientación clara que avanzará en la transformación de la matriz productiva y que a la vez mostrara grados de industrialización de un nuevo tipo con relación a los proyectos de los años 50, que no consideraban los aspectos ecológicos, ambientales y diversidad cultural. Preguntas acerca de quiénes serían los agentes de esa nueva industrialización, que ubicación tendría el empresariado nacional, los pequeños productores o la economía social y solidaria, no logran esclarecerse; asimismo, como enfrentar las importaciones ligadas a ellas. Tampoco, el rol que pudiesen cumplir nuevos sectores como fuerzas motrices para una transición hacia un sistema post-extractivista, como el turismo, fueron aclarados.

Con ese cuadro, durante los gobiernos progresistas parece haber crecido una tensión gravitante en la América Latina actual: por un lado, la expansión de las fronteras del derecho ambiental, cultural y territorial de variados pueblos indígenas; por otro lado, la expansión de las fronteras del capital para seguir explotando recursos naturales aún más costosos y que suponen intervenciones tecnológicas más agresivas (Spaldoni, 2009). Lo primero significa la defensa del hábitat natural unido a un ethos cultural, constituyentes del ser colectivo y que no pueden ser violados o pasados a llevar sino bajo el costo del debilitamiento de ese ser colectivo. Lo segundo, es desproveer de ligazón significativa un territorio y sus habitantes y verlo principalmente como espacio para eventual explotación por parte de empresas económicas movidas por la ganancia y la multiplicación de su capital, dando vida a un proceso de acumulación por desposesión.

La expresión más concreta de esta tensión es la enorme cantidad de conflictos territoriales entre grandes empresas y poblaciones locales que se han configurado en el continente, constituyendo el campo de disputa más importante (Svampa, 2016), y cuyos desenlaces pueden ejercer influencia en las eventuales orientaciones post NL. Han configurado resistencias/movimientos/organizaciones que podrán ser la base 
de proyectos post NL como: autonomía, democracia directa, multiescalas, asambleas, territorio local como bien común. ${ }^{28}$

Ya hemos dicho que las políticas sociales (e infraestructura con sentido social) y el apoyo a los más pobres ha sido una característica del período de los gobiernos progresistas. Esto incluso provocó que aumentaran las demandas sociales ${ }^{29}$. La fuente de recursos para financiar la expansión de la acción social fueron por un buen tiempo la cantidad y buenos precios de que gozaron. Ello tiene importancia en un continente donde las partes pobres de la población son altos y en que se heredaba "el costo social” de programas NL. Ello se realizó acompañado de un discurso que valorizaba a dichos sectores aumentando su capital simbólico y cierto poder en la sociedad, y podrán tener efectos estructurales positivos más adelante. Sin embargo, ya hemos dicho que ello legitimaba estrategias neoextractivistas, débiles en la defensa de sustentabilidad y que generaba zonas afectadas y de sacrificio. A la vez, este mejoramiento social no se sostuvo de manera prioritaria en una redistribución de la riqueza pues no ha estado basada en la democratización de la propiedad de los medios de producción. Por ejemplo, la distribución de la riqueza en Ecuador no ha sido relevante, particularmente la redistribución de tierra, a pesar que estaba considerada como central a partir de cierto momento del desarrollo del programa.

No obstante, lo anterior, en el periodo de los gobiernos progresistas, aun cuando no hayan cumplido sus objetivos, se amplían los imaginarios acerca de cambios que podría tener la sociedad. De Sousa Santos señala que, a partir de aquellos tenemos conceptos nuevos que no estaban a principios de siglo: buen vivir; Pachamama; derechos de la naturaleza; legalización de tierras comunales originarias; otras formas de propiedad distintas de la estatal, e individual capitalista; tres formas de democracia, representativa, participativa, y comunitaria (Boaventura de Souza, 2011). Con referencia al Buen Vivir, por ejemplo, presente en algunas constituciones, se fortalecen cuestionamientos -y la posibilidad de alternativas- al individualismo; la competencia; el consumismo, la relación con la naturaleza como objeto. O las declaraciones de Estados plurinacionales de Ecuador y Bolivia es una apertura irreversible al reconocimiento de grupos/naciones que habían quedado subalternos y desvalorizados luego del surgimiento de los Estados naciones latinoamericanos (post)coloniales.

\footnotetext{
${ }^{28}$ Esto ha tenido particulares intensidad en territorios mineros. Una multitud de estos se hicieron emblemáticos en América Latina, como: carretera Tipis en Bolivia, Famatina en Argentina; Belo Monte en Brasil; Yasuni en Ecuador, Canal de Nicaragua, Conga Perú, La Colosa, Colombia (OCMAL).

${ }^{29}$ Por ejemplo, aumentó a gratuidad de la salud en Ecuador y con ello exponencialmente la demanda de consultas y atenciones (Ospina, 2012, citando a Arroyo, Borja, Aguilar). Ejemplo: el gasto de R. Correa en sus 4 años iniciales fue más que el de los 14 años anteriores.
} 
Gana legitimidad, aunque de manera circunscrita, el cuestionamiento a un crecimiento económico infinito, aunque siga primando la idea NL que ello es casi suficiente para asegurar mejores condiciones de vida, pero gana adeptos una perspectiva de desarrollo que no se reduce a una idea central de crecimiento económico y menos si no tiene mecanismos de redistribución. En este sentido, en los últimos años en América latina resurgió la cuestión del desarrollo y de la emancipación, en un sentido más "macro"; luego de estar visto y valorizado en una mera escala local o "micro" (Svampa, 2016).

\section{Relatos interpretativos y perspectivas}

A pesar de la ampliación de horizontes e imaginarios acerca del cambio social, es evidente que una evaluación general del último decenio y medio muestra, con relación a ciertas expectativas y propósitos iniciales declarados, un avance menos significativo hacia sociedades post NL. Ello ha abierto un espacio de explicaciones aún insuficiente sobre cuáles han sido los motivos de ese "galope frustrado"; ¿por qué los cambios no ocurrieron en la velocidad o magnitud esperada? Una "respuesta" genérica y superficial es la constatación de que un proceso de cambios significativos hacia un post NL es dificultoso por factores externos e internos a dichos procesos. Pero esto debe ser mirado de manera más profunda, identificando aspectos que le den contenido a una afirmación genérica y obvia, como la anterior.

\section{Interpretaciones del "galope frustrado"}

Una línea argumentativa ha sido que las magnitudes de los cambios propuestos son de una envergadura mayor e imposibles de concretar en plazos cortos. Por ejemplo, Atilio Borón -tratando de disminuir la intensidad de las críticas a ciertos gobiernos y procesos, como el ecuatoriano y boliviano- señala que, aun por sobre lo que fueron experiencias socialistas como las de la URSS y China -además derrotadas- los propósitos de países débiles, como aquellos, fue avanzar rápido en proyectos con aspectos de refundación civilizatoria, más radicales que el del socialismo productivista..." Esto dentro de un ambiente muy desfavorable por la agresiva decadencia del poder imperial estadounidense (Borón, 2013).

A esto se puede agregar el peso de la instalación fáctica de un "hardware" NL en el continente: mercantilización, privatización, transnacionalización, etc. lo que hizo a las sociedades latinoamericanas más dependientes de las expectativas y estrategias empresariales, generando dificultades objetivas y subjetivas mayores a cambios sociales. Volviendo a algo señalado antes: la generación de un enorme 
"poder fáctico", por el solo hecho de existir, condiciona el cambio posible, y los márgenes de maniobra de programas que nacen declarativamente audaces y luego tienden a administrar lo existente, con variaciones leves.

Otra línea de argumentación destaca la dificultad de articular enunciados generales transformadores con políticas concretas que expresen a los primeros. Eso puede también ser interpretado como falta de una conexión de orientaciones de mediano plazo con acciones de corto plazo que efectivamente sean consistentes con dichas orientaciones. Se trata de un déficit de políticas concretas e inmediatas que traduzcan las propuestas y que llevan a que se produzca una brecha entre una retórica más radical que actúa como soporte ideológico y unas políticas concretas que no se diferencian tanto de las convencionales y asimilables a una gestión del NL moderado.

Esa brecha da lugar a una "interpretación” más dura de los procesos, situada en un plano fundamentalmente ético. Si lo anterior podía mostrar una incapacidad de tipo técnico que no identificaba el tipo de acciones inmediatas para avanzar en una transformación más profunda, en este caso aparece la idea del abandono del ideario e instrumentalización el discurso transformador. La dirigencia tecno-política abandona el sentido transformador enunciado para llegar al gobierno y va adaptándose al status quo, lo que genera incluso la evaluación de traición. Esto, en tanto se habrían encabezado corrientes o movimientos con ciertas ideas en que los líderes y grupos más cercanos al poder terminan por desnaturalizar y olvidar los principios y objetivos de cambio social sustantivo.

Otra perspectiva de análisis lo aporta M.E. Svampa (Svampa, 2016), la que observa las dificultades de un cambio social profundo que necesita gestionar una diversidad de "matrices ideológicas" o "narrativas" que componen la fuerza social que lo propugna. Esas matrices distintas, junto a diferenciar unos procesos de otros, hacen que cada proceso anude contradicciones fuertes en su interior, las que van apareciendo en la medida que se deben tomar decisiones que aparecen más veladas cuando dicha fuerza se conforma como oposición al NL. Esas matrices o narrativas son de tipo campesino-indígena, movimiento obrero, de clase, con centralidad de los partidos, nacional popular, con referencia al pueblo-nación, ecologistas o socio-ambientales, autonómica, libertaria, anarquista. 
Más allá de que se comparta el total de la clasificación, algo relevante es que entrega claves para comprender las dificultades para gestionar un proceso de cambio. Ello, también, puede expresarse de manera más general, como matrices antineoliberales, anticapitalistas o antimodernas. Estas diferencias se expresan en actitudes o posiciones diferentes respecto de roles del Estado, de la industrialización, de los bienes naturales, de lo comunitario, de la tecnología, del territorio, etc. constituyendo un proceso donde ciertas referencias comunes se transforman, al calor del proceso, en polisémicas. Mientras para algunos el dilema se puede expresar como la contradicción entre desarrollo versus post-desarrollo, para otros, por la disputa por el significado del desarrollo o entre exportaciones primarias versus exportaciones con valor agregado.

Otro factor que suele considerarse es un miedo al desorden social y la imagen de una sociedad que pueda ser ingobernable por un exceso de polarización. Los procesos de cambio suponen conflictos y resistencias y grados de desorden social. Si este aparece imaginado con un grado tal que no se llegará a algún objetivo de los enunciados y que todos, finalmente perderán, se puede bajar el grado de compromiso con el cambio. Se expande un temor al "costo social" de los cambios, a inestabilidades económicas y sociales, respecto de los cuales no se avizora, una compensación clara. Este es uno de los aspectos que suele ser activado por los opositores a los cambios y puede, apoyado en la memoria histórica de situaciones de grandes desequilibrios internos y externos - como inflaciones, desabastecimientos y deudas externas-terminar con políticas de fuerte impacto social negativo y que son justificadas como imprescindibles para poner orden en el país.

Una política que suele ser desprestigiada por los grupos contrarios al cambio, con el argumento que llevará a situaciones negativas para todos, es la redistributiva, de ingresos y riqueza, catalogadas de populistas y que conducirían al declive de la economía y al aumento del desempleo y de la pobreza. Esto refuerza la capacidad de veto del capital consistente en hacer "huelga", es decir, caída o desplazamiento de inversiones.

Un último factor introducido para explicar las dificultades de un avance transformador es la tensión existente entre, por un lado, los roles necesarios de un cierto liderazgo político y personal y, por otro, la necesidad de la ampliación de una fuerza colectiva organizada por el cambio. De acuerdo a lo ocurrido en estos años se puede afirmar que es importante el rol jugado por ciertos líderes en el aliento de la formación 
de colectivos. El líder juega un papel de encarnar, encausar y darle fuerza a muchos descontentos, demandas y propuestas, especialmente de la sociedad civil popular, lo que es fundamental, pues debe considerarse que los cambios, sin compromiso y movilización social, no son posibles

Sin embargo, ese liderazgo debe tener ciertas formas y límites que impidan el auto fortalecimiento continuo, hasta transformarse en un cuasi único centro de gravedad del proceso de cambios, que produce finalmente una subordinación del colectivo al líder. Este, a su vez, puesto en el centro de la escena política, tiende a debilitar la construcción más sólida de una institucionalidad que sustente cambios más allá de su propio liderazgo. Ello lleva a una personalización del poder que puede dar lugar a la figura de despotismo democrático (Tocqueville), “en que se combinan principios contradictorios de legitimidad”, generando dificultades para una organización que pueda ser autónoma de dichos liderazgos, con capacidad de enfrentar situaciones de pérdidas de popularidad y poder de aquellos (Conaghan y Malloy, 1997: 869).

Esto es clave, pues procesos de cambio sobre aspectos sustantivos, que se enfrentan a poderes macizos y dentro de sociedades con enorme desigualdad, supone generar enorme representatividad y ser un cambio “con” y “en” democracia (Herrera y Latouche, 2008). Esto implica responder a la pregunta de ¿cómo lo social transformador adquiere institucionalización y desborda liderazgos personales, y como las expresiones sociales pueden desarrollarse con autonomía del Estado, pero disputando su orientación?

\section{Notas Finales perspectivas}

Hemos destacado que en los últimos años perdió fuerza el proceso político de cuestionamiento del NL. Ello se expresaría en un giro conservador de algunos de los nuevos gobiernos del continente y del avance de las oposiciones contrarias al cambio de sistema, además, en un período de precios a la baja de los commodities que hace más difícil sustentar el uso más social de la renta. ¿Estamos finalmente en un giro conservador en que el NL retoma posiciones y hace más difícil los cambios hacia un post NL? Pienso que ciertas nuevas legitimidades en curso, propias de las últimas décadas, hace difícil la vuelta a un NL ortodoxo o puro. Al contrario, en algún grado que puede variar, el actual NL busca apelar a un apoyo social un poco mayor no solo por la integración al consumo (no fácil en este ciclo actual por la baja de los precios de los commodities) sino también a un sostén social más ideológico sostenido en argumentos como la corrupción, la transparencia, y el antipopulismo. Esto, incluso, ha sido calificado por liberales como los 
"peligros del populismo de derechas". Esto significaría que el campo de las discusiones se ha desplazado hacia orientaciones post NL, aunque de forma limitada.

Variadas demandas sociales, expresadas o latentes, marcan el continente. América latina no es el continente incendiario de los años sesenta y setenta; pero tampoco el continente "pacificado" de los decenios siguientes. Los hechos conducen a una recuperación de acciones colectivas aumentada en la mayoría de los países. Parece cerrarse o limitarse las posibilidades de seguir avanzando y aun de consolidar una sociedad autorregulada por el mercado sin el aumento de las reacciones a ello. Parte de esa activación social en el continente tiene como base un reclamo expreso al NL: a los presupuestos y/o, a las consecuencias del programa $\mathrm{NL}^{30}$. Este va siendo socialmente percibido como una ideología que sirve para dejar el campo libre a los actores empresariales y sus ganancias y abusos y no como el creador de un espacio libre de los individuos. Las referencias a lo popular, a lo nacional, a lo público, a lo ciudadano, a la igualdad, ganan más lugar en la sociedad y en casi todos los casos esa ganancia de lugar aparece en contradicción con las ideas NL.

El debilitamiento del movimiento obrero, objetivo y resultante del NL, en tanto productor de desindustrialización en varios países, no significó una extinción definitiva de contestación social que resurge desde otros agentes, causas y cauces. Surgen expresiones indígenas que han repuesto los modos comunitarios de propiedad y gestión de la economía, y las formas mismas en que se construyeron las naciones, cuestionando la mercantilización de la naturaleza; grupos ecologistas que levantan la idea de los bienes comunes - como la calidad de vida de los territorios- y ponen en cuestión la lectura liberal de "la tragedia de los comunes", según la cual solo los derechos de propiedad privada bien establecidos evitan el deterioro de la naturaleza; crecen cierta corrientes intelectuales y movimientos sociales que analizan en forma critica la inserción en el mundo y la actual globalización, retomando una lectura latinoamericana que había puesto acento en la asimetría en el plano de las relaciones económicas mundiales y formas de integración continental; múltiples localidades y regiones, urbanas y rurales, levantan demandas y generan conflictos en defensa de derechos que integran la dimensión de calidad de vida; se consolidan, maduran,

\footnotetext{
${ }^{30}$ Un ejemplo fue el caso de Bolivia, provocando lo que los autores Hylton y Thomson llamaron un "nuevo ciclo revolucionario". En el año 2000, se desarrolló la llamada guerra del agua contra el proyecto de privatización en suministro en Cochabamba, a lo que se unieron levantamientos campesinos en diversos puntos del país (véase Kohl y Farthing, 2006:169). En el año 2002 hay un masivo rechazo social al gobierno de Sánchez de Losada que, siguiendo las recomendaciones del Fondo Monetario Internacional (FMI) establece un impuesto directo de $12.5 \%$, sobre los salarios. En octubre de 2003 estallo la guerra del gas y la exigencia de su nacionalización y la resistencia frente al proyecto de exportación hacia EE.UU. por el consorcio transnacional del Pacific LNG.
} 
se hacen sujetos comunidades locales - a veces de fuerte carácter étnico- para defender derechos, como las comunidades afrodescendientes en Colombia; grandes ciudades suelen ser escenario de manifestaciones que pueden referirse a la educación, los transportes o la falta de regulaciones.

En síntesis, en el diverso mundo social, menos orgánico, se expresan descontentos y malestares, también acerca de una clase política que es vista, como señalé anteriormente, mas como parte de los poderes "de arriba", que combatiéndolos o limitándolos (Sader, 2011: 25-40). Parte de todo ello se expresa en una desconfianza social hacia las instituciones democráticas las que son vistas como habitadas por elites que hacen parte de los favorecidos, no interesados en crear situaciones equitativas en ingresos, riqueza y poder. La ampliación de conflictos de tipo territorial/ambiental han configurado en América Latina. una cartografía de la resistencia, en que debiese desprenderse que más que ser anti-desarrollo, ha colocado en el centro de la agenda política la disputa por lo que se entiende como desarrollo sustentable (Svampa, 2006)

Pareciera necesario, sin embargo, diferenciar crisis del NL de constitución de un momento/época postneoliberal. Lo primero, podríamos entenderlo como una dificultad estructural que imposibilite la reproducción del sistema a través de los pilares que definen al NL. Lo segundo, etapa post-neoliberal, significa, además, la existencia de alguna fuerza socio-política de alta magnitud, que involucre grupos dirigentes, orientada a la construcción de algún orden socio-económico, político y cultural, con grados identificables de alternatividad respecto del NL.

Pero también debiésemos agregar que, si ese debilitamiento del NL ocurriese, o está ocurriendo, en tanto pierda fuerza como ideología orientadora de las decisiones aun de sus agentes beneficiarios, no debiésemos confundir ese debilitamiento con el de estos agentes que se han fortalecido con su ejercicio durante las últimas décadas. Si la materia sólida la vemos en el capitalismo financiero, en las grandes empresas internacionales, en las tecno burocracias privadas y públicas de alto nivel, etc., que empujaron el NL, bien podría ser que una cierta atenuación de él, y aun su superación relativa, fuese deseable e impulsada por esos mismos agentes beneficiarios, habiendo ya el NL jugado un rol histórico que permitió, por ejemplo, el señalado traspaso de un enorme patrimonio público a manos privadas, una importante transnacionalización de las economías y la instalación de fuertes barreras sociales y culturales a otras alternativas. 
Por ello, una etapa post-neoliberal puede tener variantes diversas y configurar un complejo, difuso y opaco proceso y etapa transicional y debiésemos comprenderla como una etapa cuyo carácter y agentes protagonistas están en disputa.

\section{Referencias bibliográficas}

Boron, A. (2013). El Buen Vivir (Sumak Kawsay) y los dilemas de los gobiernos de izquierda en América Latina. En, América Latina en la Geopolítica del Imperialismo Buenos Aires: diciones Luxemburg.

Buendía, L., Medialdea, M.B., y otros. (2013). ¿Alternativas al neoliberalismo en América Latina?” (las políticas económicas en Venezuela, Brasil, Uruguay, Bolivia y Ecuador). Madrid/ México D.F: Fondo de Cultura Económica.

Bulmer-Thomas, V. (comp.). (1996). El nuevo modelo económico en América Latina (su efecto en la distribución del ingreso y en la pobreza). Trimestre Económico 84. México D.F: Fondo de Cultura Económica.

Burchardt, H. J. (2006). Neoextractivismo y Desarrollo: fortalezas y límites. Recuperado de:http://www.burchardt.uni-kassel.de/wpcontent/uploads/2011/09/Burchardt_Neoextractivismo_desarrollo.pdf

Cardoso, F.H y Faletto, E. (2011). Dependencia y desarrollo en América Latina. En, C. Gutiérrez (comp.), El pensamiento sobre desarrollo en América Latina. México D.F: Benemérita Universidad Autónoma de Puebla.

Conaghan C y J. Malloy. (1997). Democracia y Neoliberalismo en Perú, Ecuador y Bolivia. Desarrollo Económico. Revista de Ciencias Sociales, 36 (144), 867-890.

Déniz J., de León, O., Palazuelos, A. (2011). Nuevas estrategias económicas en América Latina (los casos de Bolivia, Ecuador y Venezuela). Madrid: Ediciones Catarata.

Devés, E. (2003). El pensamiento latinoamericano en el siglo XX. Tomo II: "Desde la CEPAL al neoliberalismo”. Buenos Aires: Centro de investigación Diego Barros Arana/ Editorial Biblos.

De Castro, S. (1992). “El Ladrillo”: bases de la política económica del gobierno militar chileno. Santiago: Centro de Estudios Públicos.

De Soto, H. (1986). El otro sendero. La revolución Informal. Lima: Instituto Libertad y Desarrollo/ Editorial El Barranco.

De Sousa Santos, B. (2011). Economía verde: la conciencia máxima del capitalismo. Entrevista a Boaventura de Sousa Santos. América Latina en movimiento, 468-469. 
(2011). La crisis de la teoría del desarrollo y las relaciones de dependencia en

América Latina. En, C. Gutiérrez (comp.), El pensamiento sobre desarrollo en América Latina. México D.F: Benemérita Universidad Autónoma de Puebla.

(2014). Reflexiones para la construcción de un intelectual de retaguardia (conversaciones con Boaventura de Sousa Santos de: J. Perret, A. Spognardi y otros). Estudios del ISHIR $\mathrm{N}^{\circ}$ 9. Buenos Aires: Conycet.

Figueroa, C. y Cordero, B. (eds.) (2011). ¿Posneoliberalismo en América Latina? (los límites de la hegemonía neoliberal en la región). México D.F: Benemérita Universidad Autónoma de Puebla. Instituto de Ciencias Sociales y Humanidades.

Friedman, M. y Friedman, R. (2008). Libertad de elegir. Madrid: Gota a Gota Ediciones.

Garretón, M. A. (2012). Neoliberalismo corregido y progresismo limitado (los gobiernos de la concertación en Chile, 1990-2010). Santiago: Editorial Arcis y Clacso.

González Meyer, R. (2004). Tres décadas de un nuevo orden económico: Chile 1973-2003. Revista Europea de Estudios Latinoamericanos y del Caribe. 77, 61-78.

(2013). Revisitando la historia de las teorías del desarrollo. Revista CUHSO, 23 (1), $55-91$.

Gutiérrez, Orlando (2006): “América Latina en la economía mundial: entre la transnacionalización y la financiarización”. Ed. Antropos, Bogotá.

Hayek, F. (2008). Camino a la Servidumbre. Madrid: Editorial Alianza.

Herrera, A.J. y Latouche, M.A. (2008). Chávez: personalismo democrático. Foreign Affairs. Latinoamérica, 8 (3), 135-144.

Hylton F y Thomson (2008). Revolutionary Horizons: Past and Presents in Bolivian Politics. Londres: Verso.

Jiménez, J. (2016). Movimiento de economía social y solidaria de Ecuador. Circuitos económicos solidarios interculturales. Revista de la Academia, 21, 101-128.

Kohl, B., y Farthing, L. (2006). Impasse in Bolivia: neoliberal hegemony and popular resistance. Londres: Book Review.

Loza, G. (2016). La experiencia boliviana y la organización comunitaria y cooperativa en el marco de la economía plural. Revista de la Academia, 21, 77-100.

Marechal, J.P. (2005). Éthique et économie. Une opposition artificielle. Rennes: PUR.

Marthoz, J. P. (2007). Ou va l'Amérique Latine (tour d'horizon d'un continent en pleine mutation). Bruselas: GRIP, Editions Complexes. 
Martínez Allier, J. (2005). El ecologismo de los pobres. Conflictos ambientales y lenguajes de valoración. Barcelona: Icaria.

Molero R. y Antolín, M.J. (2013). Entre la recuperación de la soberanía y la reproducción de los modelos productivos y distributivos. Las políticas del MAS en Bolivia, 2006-2011. En, L. Buendía, Mateo, J.P.,

Medialdea, B. y otros, ¿Alternativas al neoliberalismo en América Latina? (las políticas económicas en Venezuela, Brasil, Uruguay, Bolivia y Ecuador). Madrid/ México D.F: Fondo de Cultura Económica.

Moreira, C., Raus, D., Gómez, J.C. (coords.) (s/f). La nueva política en América Latina. Rupturas y continuidades. Montevideo: Flacso Uruguay/Universidad de Lanus/Universidad Arcis/ Editorial Trilce.

Nove, A., y Thatcher, I. (eds.). (1994). Markets and socialism. Economics, 39. Observatorio de Conflictos Mineros de América Latina (OCMAL). (s.f). Recuperado de: https://www.ocmal.org/

Ospina, P. (2012). Promesas temporales. Cambio del régimen de acumulación en Ecuador, propuestas y realizaciones de la revolución ciudadana. En L. López., M. Molina., D. Pardo., J. Piedrahita., L. Rojas.,

N. Tejaday., y R. Zelik (comps.). ¿Otros Mundos Posibles? Crisis, gobiernos progresistas, alternativas de sociedad. Medellín: Fundación Rosa Luxemburg/ Universidad Nacional de Colombia.

Palazuelos A., Villarreal, M. 2011. El proyecto de desarrollo de la revolución ciudadana. En J. Déniz., A. de León., y A. Palazuelos (eds.). Nuevas estrategias económicas en América Latina (los casos de Bolivia, Ecuador y Venezuela). Madrid: Ediciones Catarata. Polanyi, K. (2003). La Gran Transformación. Los orígenes políticos y económicos de nuestro tiempo. México D.F: Fondo de Cultura Económica.

Prebisch, R. (1963). Hacia una dinámica del desarrollo latinoamericano. México D.F: Fondo de Cultura Económica.

Preston, H. W. (1999). Una introducción a la Teoría del Desarrollo. México D.F: Siglo XXI.

Ramírez, F., Avritzer, L., y Parenti, C. (2007). Amérique latine, le tournant a gauche. Revue Mouvements, 47-48.

Sader, E. (2011). La crisis hegemónica en América Latina. En, C. Figueroa., y B. Cordero (eds.), ¿Posneoliberalismo en América Latina?” (Los límites de la hegemonía neoliberal en la región). México D.F: Benemérita Universidad Autónoma de Puebla.

Salama, P. (1999). Riqueza y Pobreza en América Latina (la fragilidad de las nuevas políticas económicas). México D.F: Fondo de Cultura Económica.

Solimano, A. (comp.). (1998). Los caminos de la prosperidad. Ensayos del crecimiento y desarrollo. Trimestre Económico 87. México D.F: Fondo de Cultura Económico. México.

Spaldoni, E. (2009). Los Conflictos socio ambientales en el contexto Latinoamericano. Fundación Cambio democrático. Recuperado de: www.initiativeforpeacebuilding.eu/.../ConflictosSocioAmbLatAm(esp). 
Stiglitz, J. (2002). La grande désillusion. París: Fayard.

Svampa, M. (2016). Debates latinoamericanos. Indianismo, desarrollo, dependencia y populismo. Buenos Aires: Edhasa.

Vázquez, G. (2016). La viabilidad y sostenibilidad de las experiencias de trabajo asociativo y autogestionado desde una perspectiva plural. Revista de la Academia, 21, 31-55. 